\title{
Visit-to-Visit Variability in Total Cholesterol Correlates with the Progression of Renal Function Decline in a Chinese Community-Based Hypertensive Population
}

\author{
Yuqin Yan ${ }^{\mathrm{a}}$ Yuqin Huang ${ }^{\mathrm{a}}$ Dan Zhou Dongtao Tang $^{\mathrm{b}}$ Ying- \\ qing Fenga \\ aDepartment of Cardiology, Guangdong Cardiovascular Institute, Hypertension Research \\ Laboratory, Guangdong Provincial Key Laboratory of Coronary Heart Disease Prevention, \\ Guangdong Provincial People's Hospital, Guangdong Academy of Medical Sciences, South \\ China University of Technology School of Medicine, Guangzhou, China; ${ }^{b}$ Community Health \\ Center of Liaobu County, Dongguan, China
}

\section{Keywords}

Total cholesterol · Variability · Kidney function · Hypertensive population · Community

\begin{abstract}
Background: Studies have demonstrated that cholesterol variability is an independent predictor of cerebrovascular and cardiovascular events. Objective: This study aimed to investigate the association of visit-to-visit variability in total cholesterol (TC) with kidney decline in a Chinese community-based population. Methods: We assessed intraindividual variability in TC among 6,465 hypertensive participants and correlated the results with endpoints. TC variability was measured using standard deviation (SD), average successive variability (ASV), coefficient of variation (CV), and variability independent of the mean (VIM). The endpoint of this study was progression of renal function decline defined as a decrease in estimated glomerular filtration rate (eGFR) $\geq 30 \%$ and to a level $<60 \mathrm{~mL} / \mathrm{min} / 1.73 \mathrm{~m}^{2}$ during follow-up if the baseline eGFR was $\geq 60 \mathrm{~mL} / \mathrm{min} / 1.73 \mathrm{~m}^{2}$, or a decrease in eGFR $\geq 50 \%$ during follow up if the baseline eGFR was $<60 \mathrm{~mL} / \mathrm{min} / 1.73 \mathrm{~m}^{2}$. Results: After a median follow-up of 27 months, $13.5 \%$ $(n=877)$ of the participants experienced progression of renal function decline. In the multivariable-adjusted Cox model, each 1-SD increase in TC variability (by SD) increased the risk of renal function decline by $11 \%(\mathrm{HR}=1.11 ; 95 \% \mathrm{Cl} 1.034-1.197 ; p=0.004)$; this was independent of the baseline eGFR, mean follow-up TC levels, and the lipid-lowering therapy. Similar results were found for the 3 other measures of variability, i.e., ASV, CV, and VIM. Conclusion: In subjects with hypertension, visit-to-visit variability in TC is an independent predictor of renal function decline.




\section{Kidney \\ Blood Pressure \\ Research}

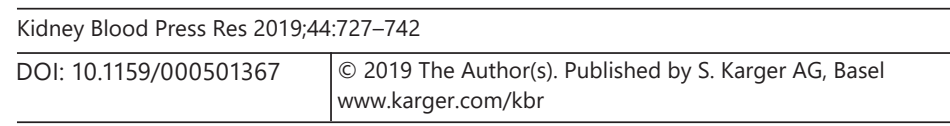

Yan et al.: TC Variability and Renal Function Decline

\section{Introduction}

Kidney disease has been recognized as a major public health burden as the population prevalence of chronic kidney disease (CKD) exceeds 10\%, and it is more than 50\% in highrisk subpopulations [1]. In the China National Survey of Chronic Kidney Disease from 2007 to 2010 , the prevalence of CKD was $10.8 \%$; that is, there are about 119.5 million patients with CKD in China [2]. As a result, identification of modifiable risk factors for CKD in the early stage is fundamental for reducing its burden. The rapid deterioration of glomerular filtration rate is a high-risk factor for adverse clinical outcomes and progression of CKD [3-5]. Moreover, the best available indicator of overall kidney function, i.e., the estimated glomerular filtration rate (eGFR), is currently used to predict the renal prognosis [6].

Recently intraindividual variability of physiological measures has attracted a lot of attention, as it has emerged as a novel health-related outcome marker. For example, increased blood pressure variability and a lowered heart rate variability have been consistently linked to adverse outcomes such as cardiovascular events, impaired cognition, and mortality [7-12]. At the same time, the evidence that intra-individual lipid variability is associated with cardiovascular events, cognitive dysfunction, stroke, and death is mounting [13-15] since a post hoc analysis from the Treating to New Targets trial evaluated patients with stable coronary artery disease and showed that visit-to-visit low-density lipoprotein cholesterol (LDL-C) variability independently predicted coronary events, cardiovascular events, death, myocardial infarction, and stroke [13]. Moreover, previous studies have indicated that lipid abnormalities may contribute to the progression of CKD $[16,17]$. In addition, hypertension is a major factor contributing to the progressive loss of kidney function, and recent analyses of clinical trials have demonstrated that variability in blood pressure predicts the progression of renal function decline [18-21]. However, whether visit-to-visit variability in total cholesterol (TC) is associated with the progression of renal function decline is currently unknown. Moreover, previous studies have evaluated the role of cholesterol variability among the general population or restricted to specific populations, but the data available in the literature on hypertensive populations are scarce and inconclusive. Hence, to better understand the association of visit-to-visit variability in TC with deterioration of renal function in patients with hypertension, we conducted a community-based hypertensive-population study involving more than 6,000 hypertensive population in China who had at least $3 \mathrm{TC}$ measurements.

\section{Subjects and Methods}

\section{Study Population}

All participants were from the Community Health Center of Liaobu County, Dongguan, China. In our study, we included subjects who had undergone a health examination between January 2010 and December $2012(n=13,729)$. All the of the recruited individuals were older than 18 years and had a definitive diagnosis of essential hypertension according to the diagnostic criteria [22]. We excluded 3,198 subjects with less than 3 health examinations from January 2010 to December 2015. We further excluded 3,767 subjects with missing data on TC. Those who had missing data on eGFR and had end-stage renal disease (ESRD; eGFR $<15 \mathrm{~mL} /$ $\min / 1.73 \mathrm{~m}^{2}$ ) were also excluded ( $\left.n=299\right)$. Finally, 6,465 eligible participants were included in this analysis (Fig. 1). In this study, each participant provided written informed consent.

\section{Collection of Demographic, Medical, and Laboratory Data}

All sociodemographic data such as age, gender, regular exercise (defined as physical activity performed at least once a week), alcohol consumption, and smoking (at baseline) were captured 
$n=13729$

Participants who had undergone a health examination during 2010-2012

3198 subjects were excluded with less than 3 health examinations

Subjects who underwent $\geq 3$ health examinations from January 2010 to December 2015

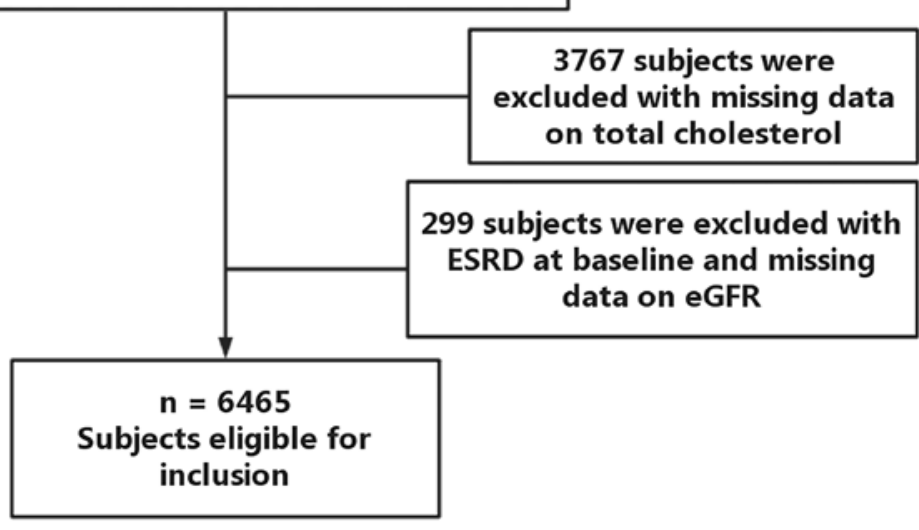

Followed from first examination to the date of Dec 31, 2015

Fig. 1. Flow chart of the study population.

from the questionnaire by community doctors. The presence of diabetes mellitus (DM) was defined according to the following criteria: (1) fasting glucose level of $7.0 \mathrm{mmol} / \mathrm{L}$ and (2) use of hypoglycemic agents to control blood glucose levels. Cerebrovascular disease was defined as a history of cerebrovascular accidents including cerebral bleeding and infarction. Coronary artery disease was defined as a history of typical angina with a positive stress test, an old myocardial infarction, or having undergone coronary artery bypass surgery or angioplasty. Use of antihypertensive agents (including diuretics, $\beta$-blockers, angiotensin-converting enzyme inhibitor [ACEi], angiotensin II receptor blockers [ARB], and calcium channel blockers [CCB]), lipid-lowering agents (statins or nonstatin drugs), and hypoglycemic agents (insulin or oral antidiabetic drugs) were also captured. Blood pressure was measured as the mean of 2 readings made in a seated position using an OMRON HBP1100u semiautomatic oscillometric recorder after resting for $5 \mathrm{~min}$. BMI was calculated as the subject's weight in kilograms divided by the square of the subject's height in meters. Blood samples were captured after an overnight fast 


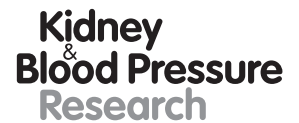

Kidney
Blood Pressure
Research

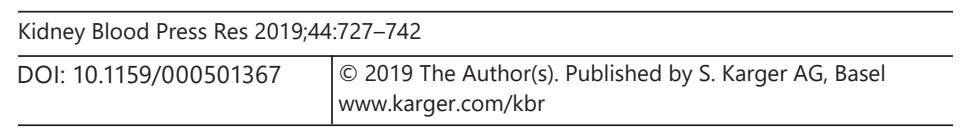

Yan et al.: TC Variability and Renal Function Decline

for the measurement of serum glucose, hemoglobin A1c (HbA1c), serum creatinine (Scr), TC, LDL-C, and high-density lipoprotein cholesterol (HDL-C) levels, among others.

\section{TC Variability}

TC variability was defined as the variation in TC values between health examinations. The following 4 measurements of variability were used: (1) the standard deviation (SD) of TC levels; (2) the average successive variability (ASV), defined as the average absolute difference between successive values; (3) coefficient of variation (CV); and (4) variability independent of the mean (VIM).VIM was calculated as $100 \times \mathrm{SD} / \mathrm{mean}^{\beta}$, where $\beta$ is the regression coefficient, using the natural logarithm of SD divided by the natural logarithm of the mean [13]. The number of TC measurements per subject ranged from 3 to 6 .

\section{Study Outcomes and Follow-Up}

Scr was captured at each health examination, and the eGFR was calculated with an equation developed by adaptation of the Modification of Diet in Renal Disease equation as follows: $\mathrm{eGFR}=175 \mathrm{Scr}^{-1.234} \cdot \mathrm{age}^{-0.179}$ (if female, 0.79) [23]. The endpoint of this study was the progression of renal function decline, defined as a decrease in eGFR $\geq 30 \%$ and to a level $<60 \mathrm{~mL} / \mathrm{min} / 1.73 \mathrm{~m}^{2}$ during follow-up if the baseline eGFR was $\geq 60 \mathrm{~mL} / \mathrm{min} / 1.73 \mathrm{~m}^{2}$, or a decrease in eGFR $\geq 50 \%$ during follow-up if the baseline eGFR was $<60 \mathrm{~mL} / \mathrm{min} / 1.73 \mathrm{~m}^{2}$ (including those who had developed ESRD [eGFR $<15 \mathrm{~mL} / \mathrm{min} / 1.73 \mathrm{~m}^{2}$ ] and a need for dialysis) [24]. Every enrollee was followed up annually and underwent health examinations, and at each visit vital signs and concurrent medication information were recorded. In addition, physical examinations and blood pressure measurements were performed and laboratory specimens, including TC, Scr, and fasting blood glucose (FBG) measurements were collected.

\section{Statistical Analysis}

In this study, all of the data analyses were performed using SAS software version 9.3 (SAS Institute, Cary, NC, USA). Continuous data are described as means \pm SD, while dichotomous variables are expressed as percentages. Student's $t$ test and the $\chi^{2}$ test were performed for continuous and discrete variables, respectively. The univariate Cox proportional hazards regression model illustrates the variable which had a significant difference with the occurrence of the outcome. In addition, we used a univariate linear regression model to identify predictors of TC variability. Then, the multivariable-adjusted Cox proportional hazards model was applied to calculate the HR for outcome per 1-SD increase in variability in TC. Model 1 was adjusted for age, sex, BMI, smoking, regular exercise, and DM. Model 2 was further adjusted for systolic blood pressure (SBP), FBG, use of antihypertensive agents, and mean follow-up TC, and model 3 was further adjusted for use of lipid-lowering agents and eGFR. The endpoint-free probability according to the quartiles of TC variability was calculated using Kaplan-Meier curves, and the log-rank test was used to analyze differences between the participants above the third quartile (IQR, P75) and below the third quartile. The potential effect modification by sex, age, obesity (defined as a BMI $\geq 25$ ), a low eGFR (defined as an eGFR of $60 \mathrm{~mL} / \mathrm{min} / 1.73 \mathrm{~m}^{2}$ ), DM, dyslipidemia medicine, and systolic pressure was evaluated through subgroup analysis and interaction testing using a likelihood ratio test. We also performed a stratified analysis to unmask medication interaction with the relationship between cholesterol variability and renal function decline. A time-dependent Cox regression was performed in order to assess whether the risk of renal function decline would vary with time. In each statistical test, $p<0.05$ (2-sided) was considered statistically significant. 
Kidney

Blood Pressure

Research

Table 1. Characteristics of the study subjects

\begin{tabular}{l|l}
\hline \multicolumn{2}{l}{ Kidney Blood Press Res 2019;44:727-742 } \\
\hline DOI: 10.1159/000501367 & $\begin{array}{l}\text { @ 2019 The Author(s). Published by S. Karger AG, Basel } \\
\text { www.karger.com/kbr }\end{array}$ \\
\hline
\end{tabular}

\begin{tabular}{|c|c|}
\hline Characteristic & Value \\
\hline Age, years & $61.96 \pm 12.92$ \\
\hline Male sex & 2,902 (44.9) \\
\hline Height, cm & $157.16 \pm 8.84$ \\
\hline Weight, kg & $62.10 \pm 12.02$ \\
\hline Waist circumference, $\mathrm{cm}$ & $87.09 \pm 9.68$ \\
\hline Hip circumference, cm & $94.54 \pm 8.03$ \\
\hline BMI & $25.04 \pm 3.83$ \\
\hline SBP, mm Hg & $135.98 \pm 18.05$ \\
\hline DBP, mm Hg & $82.79 \pm 11.08$ \\
\hline Fasting glucose, mmol/L & $5.33 \pm 1.67$ \\
\hline HbA1c, \% & $6.49 \pm 9.30$ \\
\hline Baseline triglycerides & $175.32 \pm 144.12$ \\
\hline Baseline TC, mg/dL & $198.70 \pm 42.63$ \\
\hline Baseline LDL-C, mg/dL & $105.82 \pm 30.12$ \\
\hline Baseline HDL-C, mg/dL & $50.14 \pm 14.22$ \\
\hline Mean follow-up TC, mg/dL & $205.80 \pm 37.45$ \\
\hline \multicolumn{2}{|l|}{ TC variability } \\
\hline SD & $24.95 \pm 14.86$ \\
\hline ASV & $29.25 \pm 18.53$ \\
\hline $\mathrm{CV}$ & $0.12 \pm 0.07$ \\
\hline VIM & $22.93 \pm 12.67$ \\
\hline Uric acid, $\mu \mathrm{mol} / \mathrm{L}$ & $384.59 \pm 105.42$ \\
\hline eGFR, mL/min/1.73 m² & $91.42 \pm 28.16$ \\
\hline Smoking & $1,525(23.6)$ \\
\hline Alcohol consumption & $630(9.8)$ \\
\hline Regular exercise & $2,785(52.4)$ \\
\hline DM & $1,050(16.4)$ \\
\hline Previous cerebrovascular disease & $125(2.0)$ \\
\hline Previous coronary heart disease & $92(1.5)$ \\
\hline Lipid-lowering agents & $399(6.2)$ \\
\hline Statins & $399(6.2)$ \\
\hline Nonstain drugs & $36(0.6)$ \\
\hline Antihypertensive agents & $3,540(54.8)$ \\
\hline Diuretics & $294(4.5)$ \\
\hline ACEi/ARB & $2,609(40.4)$ \\
\hline$\beta$-blockers & $538(8.3)$ \\
\hline СCB & $2,054(31.8)$ \\
\hline Antidiabetic medication & $603(9.3)$ \\
\hline Insulin & $17(0.3)$ \\
\hline Noninsulin & $594(9.2)$ \\
\hline
\end{tabular}

Data are expressed as the means \pm SD or numbers $(\%)$. The total number of subjects was 6,465 .

\section{Results}

\section{Characteristics of the Study Population}

The baseline demographics and clinical characteristics of the overall study population are shown in Table 1 . The total number of participants was 6,465 , and after a median followup of 27 months $13.5 \%$ of the participants had progression of renal function decline (according to the criteria mentioned above). The mean age at baseline was $61.96 \pm 12.92$ 
Table 2. Comparison of baseline characteristics between participants with progression and no progression of renal function decline

\begin{tabular}{|c|c|c|c|}
\hline Characteristic & $\begin{array}{l}\text { No progression } \\
(n=5,588)\end{array}$ & $\begin{array}{l}\text { Progression } \\
(n=877)\end{array}$ & $p$ value \\
\hline Age, years & $61.41 \pm 13.08$ & $65.44 \pm 11.19$ & $<0.001$ \\
\hline Male sex & $2,613(46.8)$ & $289(33.0)$ & $<0.001$ \\
\hline Height, cm & $157.47 \pm 8.90$ & $155.20 \pm 8.16$ & $<0.001$ \\
\hline Weight, kg & $62.28 \pm 12.18$ & $60.97 \pm 10.91$ & 0.001 \\
\hline Waist circumference, $\mathrm{cm}$ & $86.99 \pm 9.71$ & $87.73 \pm 9.44$ & 0.034 \\
\hline Hip circumference, $\mathrm{cm}$ & $94.44 \pm 8.03$ & $95.14 \pm 7.99$ & 0.017 \\
\hline $\mathrm{B}^{\mathrm{MI}}$ & $25.01 \pm 3.81$ & $25.27 \pm 3.90$ & 0.056 \\
\hline $\mathrm{SBP}, \mathrm{mm} \mathrm{Hg}$ & $135.12 \pm 17.94$ & $141.46 \pm 17.82$ & $<0.001$ \\
\hline $\mathrm{DBP}, \mathrm{mm} \mathrm{Hg}$ & $82.62 \pm 11.11$ & $83.91 \pm 10.81$ & 0.001 \\
\hline Fasting glucose, mmol/L & $5.32 \pm 1.64$ & $5.39 \pm 1.86$ & 0.34 \\
\hline $\mathrm{HbA} 1 \mathrm{c}, \%$ & $6.45 \pm 9.85$ & $6.82 \pm 1.75$ & 0.332 \\
\hline Baseline triglycerides & $173.02 \pm 139.98$ & $189.94 \pm 167.50$ & 0.005 \\
\hline Baseline TC, mg/dL & $198.64 \pm 41.97$ & $199.09 \pm 46.68$ & 0.789 \\
\hline Baseline LDL-C, mg/dL & $105.34 \pm 29.97$ & $108.91 \pm 30.90$ & 0.001 \\
\hline Baseline HDL-C, mg/dL & $50.01 \pm 13.78$ & $50.94 \pm 16.72$ & 0.117 \\
\hline Mean follow-up TC, mg/dL & $205.36 \pm 37.21$ & $208.61 \pm 38.85$ & 0.017 \\
\hline \multicolumn{4}{|l|}{ TC variability } \\
\hline SD & $24.37 \pm 14.62$ & $28.81 \pm 16.00$ & $<0.001$ \\
\hline ASV & $28.81 \pm 18.37$ & $32.07 \pm 19.29$ & $<0.001$ \\
\hline $\mathrm{CV}$ & $0.12 \pm 0.07$ & $0.14 \pm 0.07$ & $<0.001$ \\
\hline VIM & $22.44 \pm 12.47$ & $26.06 \pm 13.46$ & $<0.001$ \\
\hline Uric acid, $\mu \mathrm{mol} / \mathrm{L}$ & $385.87 \pm 106.50$ & $376.38 \pm 97.92$ & 0.009 \\
\hline $\mathrm{eGFR}, \mathrm{mL} / \mathrm{min} / 1.73 \mathrm{~m}^{2}$ & $92.41 \pm 29.07$ & $85.08 \pm 20.31$ & $<0.001$ \\
\hline Smoking & $1,367(24.5)$ & $158(18.0)$ & $<0.001$ \\
\hline Alcohol consumption & $584(10.5)$ & $46(5.2)$ & $<0.001$ \\
\hline Regular exercise & $2,408(51.8)$ & $377(56.5)$ & 0.022 \\
\hline $\mathrm{DM}$ & $907(16.4)$ & $143(16.5)$ & 0.94 \\
\hline Previous cerebrovascular disease & $107(2.0)$ & $18(2.2)$ & 0.746 \\
\hline Previous coronary heart disease & $70(1.3)$ & $22(2.6)$ & 0.003 \\
\hline Lipid-lowering agents & $377(6.7)$ & $22(2.5)$ & $<0.001$ \\
\hline Statins & $377(6.7)$ & $22(2.5)$ & $<0.001$ \\
\hline Nonstatin drugs & $33(0.6)$ & $3(0.3)$ & 0.358 \\
\hline Antihypertensive agents & $2,995(53.6)$ & $545(62.1)$ & $<0.001$ \\
\hline Diuretics & $250(4.5)$ & $44(5)$ & 0.473 \\
\hline ACEi/ARB & $2,222(39.8)$ & $387(44.1)$ & 0.014 \\
\hline$\beta$-blockers & $438(7.8)$ & $100(11.4)$ & $<0.001$ \\
\hline $\mathrm{CCB}$ & $1,730(31.0)$ & $324(36.9)$ & $<0.001$ \\
\hline Antidiabetic medication & $552(9.9)$ & $51(5.8)$ & $<0.001$ \\
\hline Insulin & $16(0.3)$ & $1(0.1)$ & 0.354 \\
\hline Noninsulin & $543(9.7)$ & $51(5.8)$ & $<0.001$ \\
\hline
\end{tabular}

years and the population was $44.9 \%$ male. All of the participants were adults with hypertension, $16.4 \%$ of them had DM, $1.5 \%$ of them had a history of coronary heart disease, and $2 \%$ had a history of cerebrovascular disease. The baseline TC and mean follow-up TC values for the study population were $198.70 \pm 42.63$ and $205.80 \pm 37.45 \mathrm{mg} / \mathrm{dL}$, respectively. Nevertheless, only $6.2 \%$ of the subjects were taking lipid-lowering drugs at baseline. Table 2 shows the comparison of baseline characteristics between participants with progression and no progression of kidney function decline. Patients in the progression group were older 
Kidney

Blood Pressure

Research

Table 3. Univariate Cox regression analysis for progression of renal function decline

\begin{tabular}{l|l}
\hline \multicolumn{2}{l}{ Kidney Blood Press Res 2019;44:727-742 } \\
\hline DOI: 10.1159/000501367 & $\begin{array}{l}\text { @ 2019 The Author(s). Published by S. Karger AG, Basel } \\
\text { www.karger.com/kbr }\end{array}$ \\
\hline
\end{tabular}

\begin{tabular}{llc}
\hline Predictor variable & \multicolumn{2}{l}{$\begin{array}{l}\text { Progression of renal function } \\
\text { decline }\end{array}$} \\
\cline { 2 - 3 } & HR $(95 \%$ CI) & $p$ value \\
\hline Female sex & $1.50(1.31-1.73)$ & $<0.001$ \\
Age (years) & $1.03(1.02-1.03)$ & $<0.001$ \\
BMI & $0.99(0.97-1.01)$ & 0.295 \\
Smoking & $0.83(0.70-0.99)$ & 0.366 \\
Alcohol consumption & $0.77(0.57-1.04)$ & 0.086 \\
Regular exercise & $0.96(0.83-1.12)$ & 0.636 \\
DM & $1.30(1.09-1.56)$ & 0.004 \\
HbA1c (mmol/mol) & $1.00(0.98-1.02)$ & 0.674 \\
Fasting blood glucose (mmol/L) & $0.98(0.94-1.02)$ & 0.39 \\
Systolic BP (mm Hg) & $1.00(1.00-1.00)$ & 0.854 \\
Baseline triglycerides (mg/dL) & $1.00(1.00-1.00)$ & 0.708 \\
Baseline TC (mg/dL) & $1.00(1.00-1.00)$ & 0.014 \\
Mean follow-up TC (mg/dL) & $1.00(1.00-1.00)$ & 0.001 \\
eGFR (mL/min/1.73 m $\left.{ }^{2}\right)$ & $1.00(0.99-1.00)$ & 0.01 \\
Lipid-lowering agents & $1.18(0.77-1.81)$ & 0.457 \\
Statins & $1.18(0.77-1.81)$ & 0.457 \\
Nonstatin drugs & $1.68(0.54-5.22)$ & 0.371 \\
Antihypertensive agents & $0.96(0.84-1.10)$ & 0.548 \\
Diuretics & $1.14(0.84-1.55)$ & 0.384 \\
ACEI/ARB & $0.97(0.84-1.10)$ & 0.606 \\
B-blockers & $1.12(0.91-1.38)$ & 0.279 \\
CCB & $0.96(0.84-1.10)$ & 0.569 \\
TC variability $\quad$ & $1.16(1.09-1.23)$ & $<0.001$ \\
$\quad$ SD & $1.15(1.08-1.23)$ & $<0.001$ \\
$\quad$ ASV & $1.14(1.06-1.21)$ & $<0.001$ \\
$\quad$ VV & $1.14(1.07-1.22)$ & $<0.001$ \\
\hline & & \\
\hline & &
\end{tabular}

$(p<0.001)$ and more likely to be female and have a history of coronary heart disease $(p=$ $0.003)$, as well as higher SBP ( $p<0.001)$, diastolic blood pressure (DBP) ( $p=0.001)$, and triglyceride $(p=0.005)$ values and lower eGFR $(p<0.001)$ values than those in the no-progression group. In addition, patients with renal function decline were more frequently treated with ACEi/ARB, $\beta$-blockers, and CCB, whereas the same subjects were less frequently treated with statins and oral hypoglycemic agents. Baseline TC levels were similar for the progression and no-progression groups $(p=0.789)$, while the mean follow-up TC levels were higher in the progression group ( $p=0.017)$. All of the measures of visit-to-visit TC variability (including CV, SD, ASV, and VIM) for the progression group were significantly higher than for the no-progression group $(p<0.001)$.

\section{Determinants of Renal Function Decline}

The relationship between clinical parameters and the endpoint was assessed by univariate Cox regression analysis, as shown in Table 3 . The risk of a decline in renal function was significantly higher among participants who were female ( $\mathrm{HR}=1.5 ; 95 \% \mathrm{CI} 1.31-1.73$ ) and older ( $\mathrm{HR}=1.03 ; 95 \% \mathrm{CI} 1.02-1.03)$, had a history of diabetes (HR $=1.30 ; 95 \% \mathrm{CI} 1.09-1.56)$, and had a higher TC variability (described by SD [HR = 1.16; 95\% CI 1.09-1.23], ASV [HR = 1.15; 95\% CI 1.08-1.23], and CV [HR $=1.14 ; 95 \%$ CI 1.06-1.21], VIM [HR $=1.14 ; 95 \%$ CI $1.07-$ 
Table 4. Univariate simple linear regression for individual predictors of TC variability

\begin{tabular}{|c|c|c|c|c|c|c|c|c|}
\hline \multirow[t]{2}{*}{ Independent variable } & \multicolumn{2}{|l|}{ SD } & \multicolumn{2}{|l|}{ ASV } & \multicolumn{2}{|l|}{$\mathrm{CV}$} & \multicolumn{2}{|l|}{ VIM } \\
\hline & $\beta$ & $p$ value & $\beta$ & $p$ value & $\beta$ & $p$ value & $\beta$ & $p$ value \\
\hline Age (years) & 0.0083 & 0.56 & 0.024 & 0.18 & -0.00003 & 0.67 & -0.004 & 0.75 \\
\hline Female sex & 2.32 & $<0.0001$ & 2.09 & $<0.0001$ & 0.003 & 0.05 & 0.81 & 0.01 \\
\hline BMI & 0.25 & $<0.0001$ & 0.24 & $<0.0001$ & 0.0002 & $<0.0001$ & 0.21 & $<0.0001$ \\
\hline Smoking & -1.61 & 0.0002 & -0.89 & 0.10 & -0.004 & 0.03 & -0.87 & 0.02 \\
\hline Alcohol consumption & -0.54 & 0.38 & 0.16 & 0.84 & -0.002 & 0.58 & -0.32 & 0.55 \\
\hline Regular exercise & 0.92 & 0.026 & 0.85 & 0.10 & 0.004 & 0.06 & 0.69 & 0.05 \\
\hline Fasting blood-glucose & 0.91 & $<0.0001$ & 0.89 & $<0.0001$ & 0.004 & $<0.0001$ & 0.72 & $<0.0001$ \\
\hline $\operatorname{HbA1c}(\%)$ & 0.02 & 0.75 & 0.03 & 0.72 & 0.00002 & 0.94 & 0.006 & 0.91 \\
\hline SBP (mm Hg) & 0.06 & $<0.0001$ & 0.03 & 0.01 & 0.0003 & $<0.0001$ & 0.05 & $<0.0001$ \\
\hline DBP (mm Hg) & 0.06 & 0.0003 & 0.03 & 0.20 & 0.0002 & 0.002 & 0.04 & 0.002 \\
\hline Baseline TC (mg/dL) & 0.08 & $<0.0001$ & 0.09 & $<0.0001$ & -0.00005 & 0.007 & -0.0004 & 0.91 \\
\hline Mean follow-up TC (mg/dL) & 0.12 & $<0.0001$ & 0.14 & $<0.0001$ & -0.00005 & 0.04 & 0.005 & 0.25 \\
\hline Uric acid $(\mu \mathrm{mol} / \mathrm{L})$ & 0.002 & 0.38 & 0.004 & 0.07 & 0.00001 & 0.19 & 0.002 & 0.22 \\
\hline eGFR (mL/min/1.73 m²) & -0.02 & 0.006 & -0.01 & 0.24 & -0.0001 & 0.0009 & -0.02 & 0.001 \\
\hline DM & 4.10 & $<0.0001$ & 5.20 & $<0.0001$ & 0.02 & $<0.0001$ & 3.64 & $<0.0001$ \\
\hline Lipid-lowering agents & 3.69 & $<0.0001$ & 6.58 & $<0.0001$ & 0.02 & $<0.0001$ & 4.04 & $<0.0001$ \\
\hline
\end{tabular}

1.22]). Not unexpectedly, the use of antihypertensive agents, especially ACEi/ARB, slowed the progression of kidney function decline, though it did not reach statistical significance $(\mathrm{HR}=0.97 ; p=0.606)$.

\section{Predictors of Visit-to-Visit TC Variability}

Simple linear regression analysis of TC variability is shown in Table 4. TC variability was significantly associated with sex, BMI, a history of DM, and lipid-lowering therapy. Moreover, the higher the SBP and FBG values were, the higher the TC variability was, while there was a negative correlation between the baseline eGFR and TC variability. No correlations between visit-to-visit TC variability and age, drinking, or uric acid were observed.

\section{Visit-to-Visit TC Variability and Progression of Renal Function}

Figure 2 is a forest plot of the HR of TC variability using 4 different measures of variability with and without adjustment for demographic characteristics and other confounding factors. In the unadjusted model, visit-to-visit variability in TC was associated with a significant increase in the risk of renal function decline. For every 1-SD increase in TC variability (as measured by SD), the risk of renal function decline increased by $14 \%$ (HR $=1.14 ; 95 \% \mathrm{CI}$ $1.07-1.22 ; p<0.001$ ). Furthermore, visit-to-visit TC variability as measured by SD was an independent predictor of progression of renal function decline even after adjusting for age, sex, BMI, smoking, regular exercise, DM (HR = 1.13; 95\% CI 1.058-1.211; $p<0.001)$. After further controlling for other confounding factors, including SBP, FBG, use of antihypertensive agents, mean follow-up TC, use of lipid-lowering agents, and baseline eGFR, the association between cholesterol variability and the endpoint remained significant (HR $=1.11 ; 95 \% \mathrm{CI}$ 1.034-1.197; $p=0.004$ ). TC variability as measured by ASV, CV, or VIM was also an independent predictor of kidney function decline, even after full multivariable adjustment. Furthermore, the incidence rate of outcomes was higher in the group with TC variability above the third quartile (IQR, P75) compared to the group with TC variability below the P75, indicating that the higher the TC variability was, the faster the kidney function deterioration occurred (Fig. 3). 


\begin{tabular}{|c|ccccccc}
\hline \begin{tabular}{l}
\hline \\
TC Variability Adjusted Model \\
SD TC
\end{tabular} Crude model \\
Model 1 \\
Model 2 \\
Model 3
\end{tabular}

Fig. 2. TC variability and risk of renal function decline. For every 1-SD increase in TC variability, the risk of renal function decline increased in the crude model and in adjusted models 1, 2, and 3. Model 1 was adjusted for age, sex, BMI, smoking, regular exercise, and DM; model 2 was further adjusted for SBP, FBG, use of antihypertensive agents, and mean follow-up TC; model 3 was further adjusted for use of lipid-lowering agents and eGFR.

\section{Subgroup Analyses}

Stratified analyses were performed to further assess the relationship between TC variability and renal function decline in various subgroups. None of the variables, including age ( 60 vs. 60 years; $p$ for interaction $=0.4775)$, $\operatorname{sex~}(p$ for interaction $=0.2888)$, obesity $(p$ for interaction $=0.2608)$, DM ( $p$ for interaction $=0.6578)$, dyslipidemia medicine $(p$ for interaction $=0.9431$ ), low eGFR ( $p$ for interaction $=0.0596)$, or blood pressure levels ( $p$ for interaction $=0.9281$ ) significantly modified the association between TC variability (by SD) and the endpoint. These findings were consistent when using other indices of variability, including ASV, CV, and VIM (Fig. 4). To account for the possible influence of medications on the relationship between variability in TC and the endpoint, we performed a subgroup analysis based on different drug types. The associations between TC variability and renal function decline were consistent across various drug subgroups. There were no significant interactions in any of the 11 predefined subgroups ( $p>0.10$ for all comparisons). These findings were consistent no matter which indices of variability were used (Fig. 5).

\section{Sensitivity Analyses}

The results were similar in the sensitivity analyses that used TC variability as a timedependent covariate. For every 1-SD increase in TC variability (as measured by SD), the risk of renal function decline increased by $15 \%(p<0.001)$. After controlling for multiple variables, the risk increased by $11 \%$ (online suppl. Table 1; for all online suppl. material, see www.karger.com/doi/10.1159/000501367). 


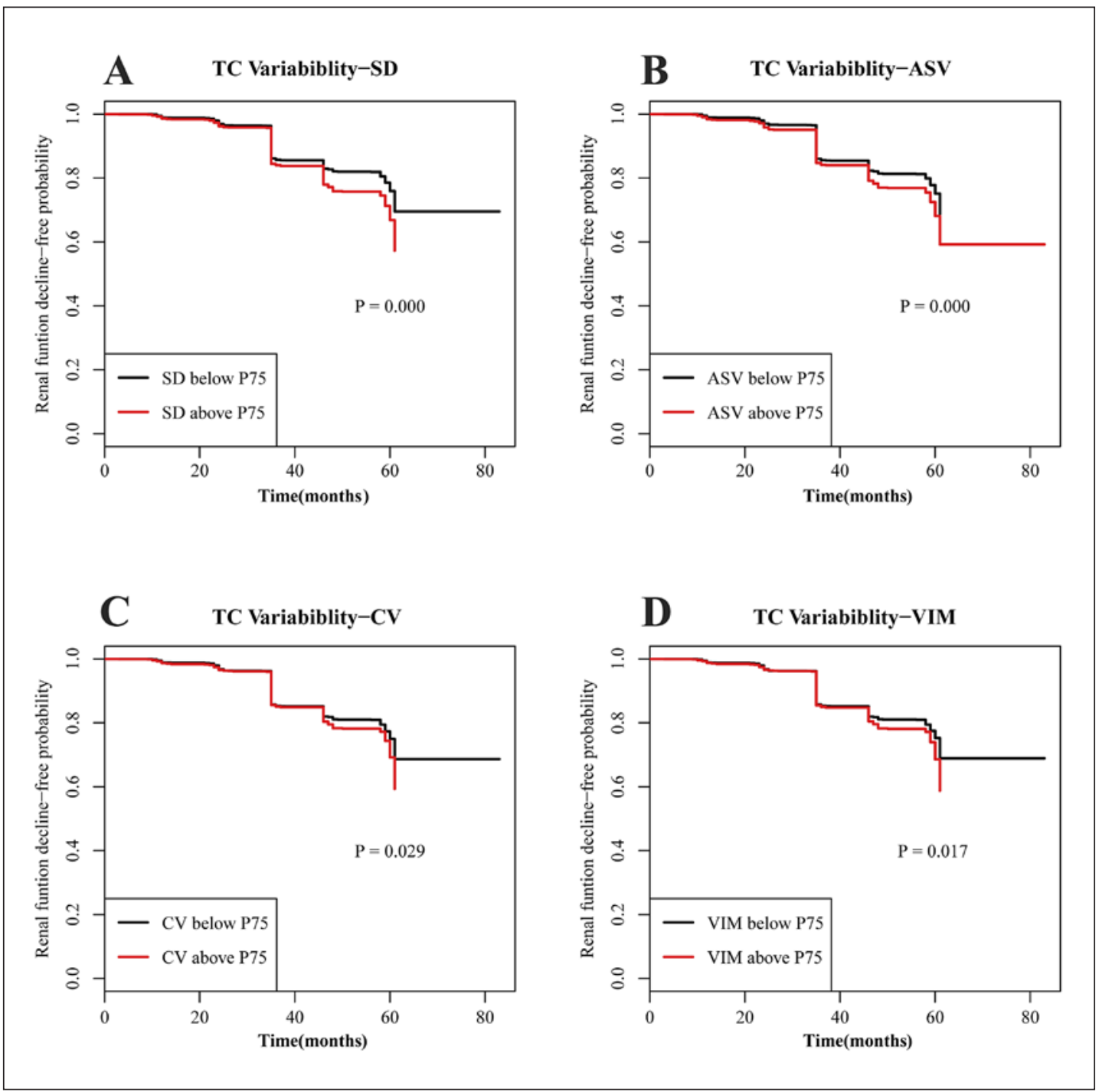

Fig. 3. Kaplan-Meier curves for progression of renal function decline. Kaplan-Meier estimates for renal function decline for participants whose TC variability was above the third quartile (IQR, P75) or below the third quartile. TC variability was measured as SD (A), ASV (B), CV (C), and VIM (D).

\section{Discussion}

In the present study, we enrolled 6,465 hypertensive patients in a community of China, most of whom had a normal kidney function at baseline. We demonstrated that TC variability was an independent predictor of progression of renal function decline, even after multivariable adjustment for potential confounding factors, including blood pressure level, baseline eGFR, and lipid-lowering therapy. In the full adjustment model, for every 1-SD increase in TC variability (as measured by SD) the risk of the endpoint increased by $11 \%$. Of particular importance, the results obtained using different indices of TC variability were consistent. To the best of our knowledge, this analysis is the first to demonstrate the association between lipid variability and renal function decline in hypertensive patients and add to the evidence that visit-to-visit variability in TC is a predictor of cardiovascular events. 


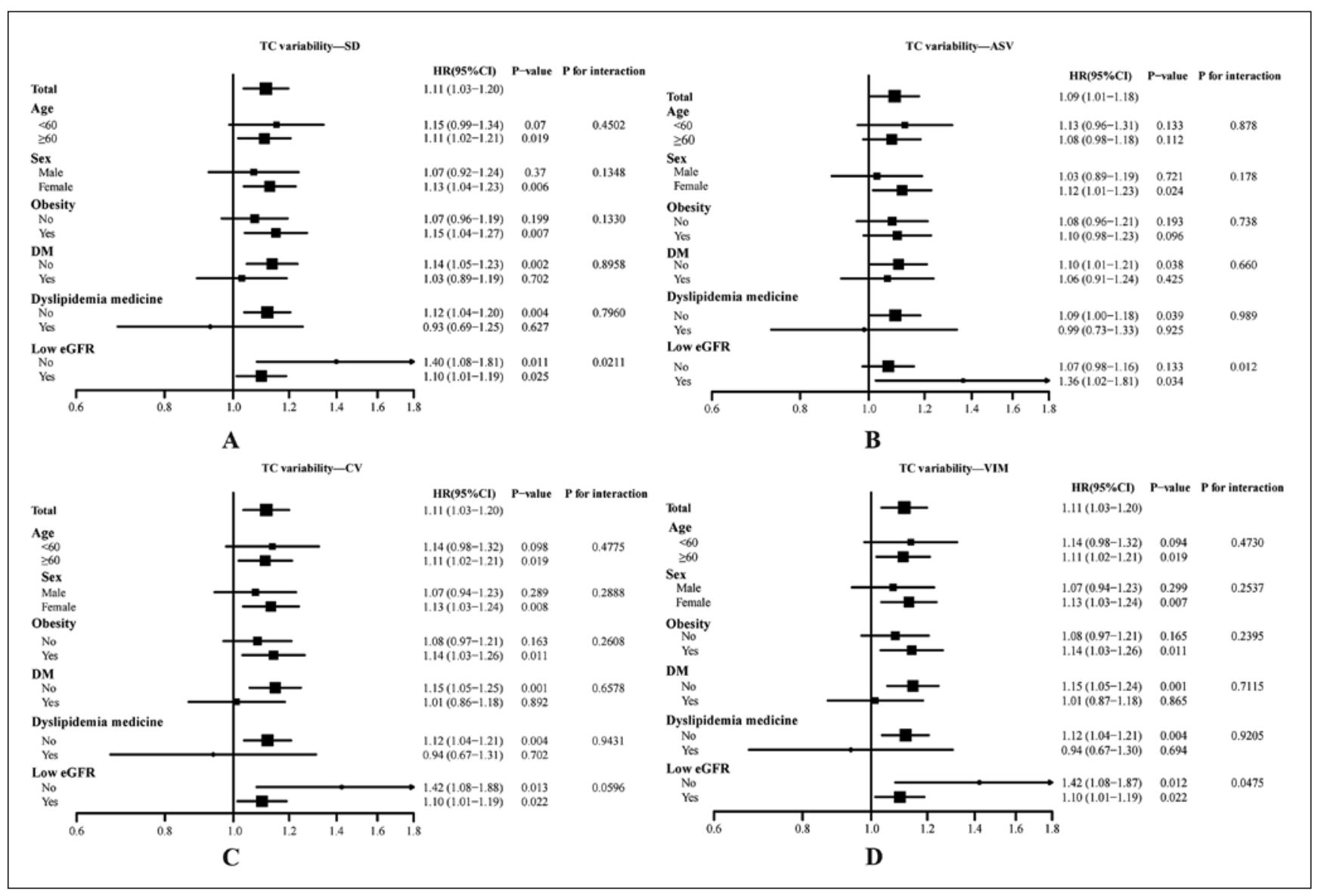

Fig. 4. HR for renal function decline in subgroups, adjusted for age, sex, BMI, smoking, regular exercise, DM, SBP, FBG, use of antihypertensive agents, mean follow-up TC, use of lipid-lowering agents, and eGFR. TC variability was measured as SD (A), ASV (B), CV (C), and VIM (D).

Intraindividual variability in biological parameters such as BP variability and heart rate variability has been recognized as a new biometric. Studies have shown that short- or longterm visit-to-visit variability in BP portends a worsening prognosis and that a greater BP variability is associated with an increased risk of cardiovascular events, stroke, and death in those with hypertension [25, 26]. A 15-year retrospective cohort study conducted by Chia et al. [19] showed that variability in blood pressure accelerates the deterioration of kidney function and contributes to the progression of CKD independently of the blood pressure [19]. Similarly to $\mathrm{BP}$, visit-to-visit variability in cholesterol portends a worsening prognosis; however, the data on cholesterol variability and prognosis are limited. Evidence from the Treating to New Targets trial suggested that a greater LDL-C variability was a strong predictor of coronary events, myocardial infarction, stroke, and death in patients with known coronary artery disease [13]. In the IDEAL trial, which enrolled patients with a previous myocardial infarction, showed that variability in LDL-C was closely related to adverse outcomes including coronary events, myocardial infarction, stroke, and death [26]. The Prospective Study of Pravastatin in the Elderly at Risk showed that a higher LDL-C variability was closely related to a lower neurocognitive performance, a lower cerebral blood flow, and greater white matter hyperintensity on brain magnetic resonance imaging [14]. The relationship between cholesterol vari- 


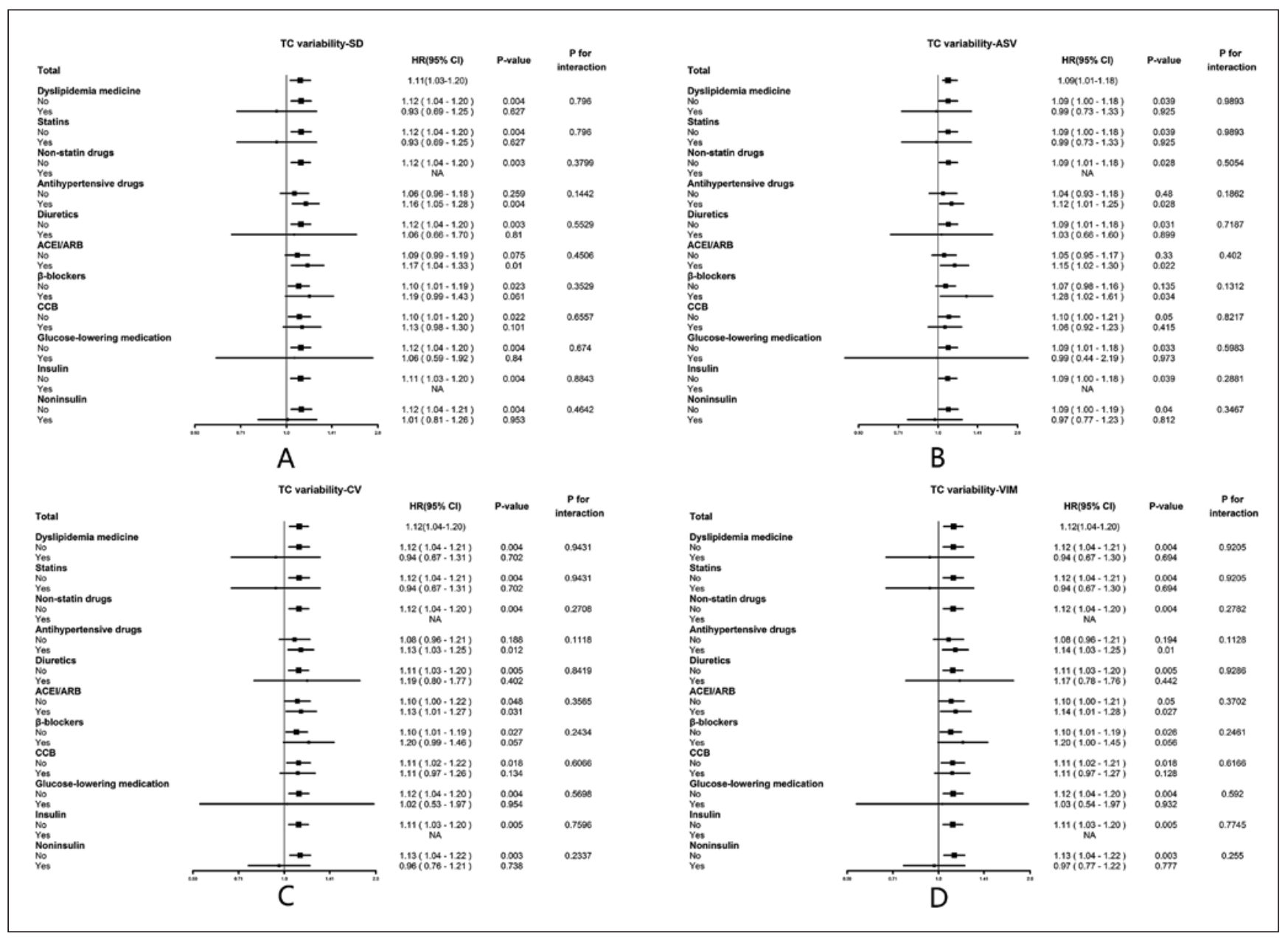

Fig. 5. Renal function decline across various drug subgroups, adjusted for age, sex, BMI, smoking, regular exercise, DM, SBP, FBG, use of antihypertensive agents, mean follow-up TC, use of lipid-lowering agents, and eGFR. TC variability was measured as SD (A), ASV (B), CV (C), and VIM (D).

ability and cardiovascular events now seems established. Nevertheless, the data available in the literature on the effects of lipid variability on renal dysfunction is scarce. Analysis form a national population-based study in Korea demonstrated that TC variability was a determinant of ESRD independently of preexisting CKD [27]. Our results add supportive data on the relevance of TC variability and kidney disease and extend the previous study by showing that, among hypertensive patients (with or without a low eGFR), those with a high TC variability were more likely to have progression of renal function decline. It is widely accepted that hypertension and DM are essential to accelerate the deterioration of renal function. In our study, after blood pressures, a history of DM, use of antihypertensive drugs, FBG, and other confounders had been fully adjusted, TC variability was still linked to kidney function decline. It is worth noting that this is in contrast to data from prior research, in which lipidlowering treatments have a protective effect against the progression of renal function decline $[16,17]$. However, the results we obtained are relevant, albeit with a lack of significance ( $p=$ $0.457)$. A possible explanation for this finding is that very few participants used the lipidlowering agents at baseline $(n=399,6.2 \%)$ and most of the patients started lipid-lowering 


\section{Kidney \\ Blood Pressure \\ Research}

\begin{tabular}{l|l}
\hline Kidney Blood Press Res 2019;44:727-742 \\
\hline DOI: 10.1159/000501367 & $\begin{array}{l}\text { ○ 2019 The Author(s). Published by S. Karger AG, Basel } \\
\text { www.karger.com/kbr }\end{array}$ \\
\hline
\end{tabular}

Yan et al.: TC Variability and Renal Function Decline

therapy later on. Another explanation for the observed discrepancy is poor medication compliance; in China, especially in the Chinese community, it is common for patients to stop taking pills at will. Moreover, lipid-lowering therapy might be related to the high TC variability, which has been shown in the simple linear regression analysis of TC variability from our data as well. Also, it is likely that the beneficial effects of the use of statins is mitigated by the impact of the high TC variability.

Moreover, in the univariate Cox regression analyses, SBP and FBG at baseline had little effect on the progression of renal function decline. However, a history of DM is a remarkable risk factor for renal function decline. One explanation could account for all these oddities. All of the participants had hypertension, and some patients took antihypertensives and antidiabetic agents at baseline. Then, some of them stopped taking these pills at will and those who were not using blood pressure-lowering medications or hypoglycemic drug at baseline may have started the treatment then. As a result, the association between SBP (or FBG) at baseline and renal function deterioration is weak.

The biological mechanisms underlying TC variability and the correlation to the progression of kidney function decline warrants further investigation, and several explanations could be suggested. Hypertension, endothelial dysfunction, inflammation, and oxidative stress, which are the same pathophysiological factors that lead to atherosclerosis, are believed to be the principal causal mechanisms of kidney dysfunction $[28,29]$. Recent studies suggest that a higher cholesterol variability is associated with a lower cerebral blood flow but also with a greater white matter hyperintensity load, which has been linked to endothelial dysfunction [14]. Therefore, one pathway could be through endothelial dysfunction, which plays a vital role in renal function decline [30,31]. Lipid deposition and the appearance of foam cells in glomeruli accompany kidney injury in models of hyperlipidemia [29, 32]. Fluctuations in blood cholesterol may contribute to the renal function decline directly, owing to the instability of vascular wall led by the fluctuations in the composition of lipid deposits [27]. It is noteworthy that, although TC variability is a predominant risk factor for renal function decline, the potential for causality reversal needs to be noted. It is hard to exclude the possibility that renal disease increases lipid variability since impaired kidney function exhibits increased concentrations of lipids and a required LDL-C receptor deficiency [33]. Moreover, patients who have a faster renal function decline might have a greater TC variability in virtue of their lipid metabolism changes.

There are some distinguishing points of this study. First, it has a relatively large size, i.e., more than 6,000 hypertensive patients, which is large enough to show the association between TC variability and progression of kidney function decline in patients with hypertension. Second, it is the first study to evaluate the influence of cholesterol variability on renal function decline in hypertensive residents of a Chinese community. Finally, we collected the eGFR and assessed the renal function at each visit; frequent renal function assays allows a more accurate assessment of changes in kidney function over time. Several limitations of the current analysis warrant consideration. First of all, our results were based on post hoc analyses, and causality cannot be determined. However, in order to minimize the possible effects of reverse causality, subjects with an eGFR $<15 \mathrm{~mL} / \mathrm{min} / 1.73 \mathrm{~m}^{2}$ at baseline were excluded, and the subgroup analyses were conducted in patients with a low eGFR or without a low eGFR. Second, we failed to provide baseline microalbuminuria or urinary albumin data, which are closely associated with kidney function decline. Third, it is the lack of plausible mechanisms whereby the variability of cholesterol levels in people not on lipid medication might bear a causative relationship with renal decline. Lastly, the participants were limited to hypertensive residents in a Chinese community; it is uncertain whether these findings can be extrapolated to other groups. 


\section{Kidney \\ Blood Pressure Research}

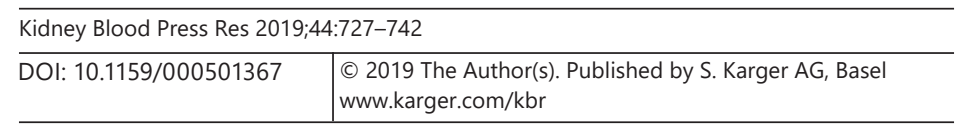

Yan et al.: TC Variability and Renal Function Decline

\section{Conclusion}

Visit-to-visit variability in TC is important in determining the progression of kidney function deterioration in patients with hypertension. Patients with a higher TC variability had a higher incidence of progression of kidney function decline compared to those with a lower variability in TC. However, well-designed prospective studies are required to further clarify the link between cholesterol variability and renal function decline and to determine the mechanisms accounting for this association. Also, further studies are badly needed to figure out how to measure cholesterol variability and the accepted "normal" value for cholesterol variability.

\section{Acknowledgment}

We thank all of the study participants. This work was supported by the Natural Science Foundation of Guangdong Province (No. 2015A030313660), the Science and Technology Program of Guangzhou (No. 201604020143, No. 201604020018, No. 201604020186, No. 201510010254, and No. 201803040012), the Medical Science and Technology Research Fund of Guangdong Province (No. B2018023), the National Key Research and Development Program of China (No. 2017YFC1307603 and No. 2016YFC1301305), and the Science and Technology Program of Guangdong Province (No. 2014B020212008).

\section{Statement of Ethics}

All of the subjects gave their written informed consent, and this study protocol was approved by the research institute's committee on human research.

\section{Disclosure Statement}

The authors declare no conflict of interests.

\section{Author Contributions}

Y.F. chaired and led all of the investigations and oversaw all trial activities. Y.Y. wrote and edited the primary article and did all of the analyses. Y.H., D.Z., and S.T. oversaw the daily trial activities and data collection. Y.Y., Y.F., and Y.H. assisted in the study design and data interpretation and provided comments on the final article. All of the authors approved the final version of this paper.

\section{References}

1 Levey AS, Coresh J. Chronic kidney disease. Lancet. 2012 Jan;379(9811):165-80.

2 Zhang L, Wang F, Wang L, Wang W, Liu B, Liu J, et al. Prevalence of chronic kidney disease in China: a crosssectional survey. Lancet. 2012 Mar;379(9818):815-22.

3 Lambers Heerspink HJ, Tighiouart H, Sang Y, Ballew S, Mondal H, Matsushita K, et al. GFR decline and subsequent risk of established kidney outcomes: a meta-analysis of 37 randomized controlled trials. Am J Kidney Dis. 2014 Dec;64(6):860-6. 


\begin{tabular}{l|l}
\hline \multicolumn{2}{l}{ Kidney Blood Press Res 2019;44:727-742 } \\
\hline DOI: 10.1159/000501367 & $\begin{array}{l}\text { @ 2019 The Author(s). Published by S. Karger AG, Basel } \\
\text { www.karger.com/kbr }\end{array}$ \\
\hline
\end{tabular}

Yan et al.: TC Variability and Renal Function Decline

4 Inker LA, Lambers Heerspink HJ, Mondal H, Schmid CH, Tighiouart H, Noubary F, et al. GFR decline as an alternative end point to kidney failure in clinical trials: a meta-analysis of treatment effects from 37 randomized trials. Am J Kidney Dis. 2014 Dec;64(6):848-59.

5 Muntner P, He J, Hamm L, Loria C, Whelton PK. Renal insufficiency and subsequent death resulting from cardiovascular disease in the United States. J Am Soc Nephrol. 2002 Mar;13(3):745-53.

6 Yahalom G, Kivity S, Segev S, Sidi Y, Kurnik D. Estimated glomerular filtration rate in a population with normal to mildly reduced renal function as predictor of cardiovascular disease. Eur J Prev Cardiol. 2014 Aug;21(8): 941-8.

7 Gosmanova EO, Mikkelsen MK, Molnar MZ, Lu JL, Yessayan LT, Kalantar-Zadeh K, et al. Association of Systolic Blood Pressure Variability With Mortality, Coronary Heart Disease, Stroke, and Renal Disease. J Am Coll Cardiol. 2016 Sep;68(13):1375-86.

8 Kim DH, Lipsitz LA, Ferrucci L, Varadhan R, Guralnik JM, Carlson MC, et al. Association between reduced heart rate variability and cognitive impairment in older disabled women in the community: Women's Health and Aging Study I. J Am Geriatr Soc. 2006 Nov;54(11):1751-7.

9 Muntner P, Shimbo D, Tonelli M, Reynolds K, Arnett DK, Oparil S. The relationship between visit-to-visit variability in systolic blood pressure and all-cause mortality in the general population: findings from NHANES III, 1988 to 1994. Hypertension. 2011 Feb;57(2):160-6.

10 Tsuji H, Larson MG, Venditti FJ Jr, Manders ES, Evans JC, Feldman CL, et al. Impact of reduced heart rate variability on risk for cardiac events. The Framingham Heart Study. Circulation. 1996 Dec;94(11):2850-5.

11 Rothwell PM, Howard SC, Dolan E, O’Brien E, Dobson JE, Dahlöf B, et al. Prognostic significance of visit-to-visit variability, maximum systolic blood pressure, and episodic hypertension. Lancet. 2010 Mar;375(9718):895905.

12 Tai C, Sun Y, Dai N, Xu D, Chen W, Wang J, et al. Prognostic significance of visit-to-visit systolic blood pressure variability: a meta-analysis of 77,299 patients. J Clin Hypertens (Greenwich). 2015 Feb;17(2):107-15.

13 Bangalore S, Breazna A, DeMicco DA, Wun CC, Messerli FH, Committee TN; TNT Steering Committee and Investigators. Visit-to-visit low-density lipoprotein cholesterol variability and risk of cardiovascular outcomes: insights from the TNT trial. J Am Coll Cardiol. 2015 Apr;65(15):1539-48.

14 Smit RA, Trompet S, Sabayan B, le Cessie S, van der Grond J, van Buchem MA, et al. Higher Visit-to-Visit LowDensity Lipoprotein Cholesterol Variability Is Associated With Lower Cognitive Performance, Lower Cerebral Blood Flow, and Greater White Matter Hyperintensity Load in Older Subjects. Circulation. 2016 Jul;134(3): 212-21.

15 Kim MK, Han K, Kim HS, Park YM, Kwon HS, Yoon KH, et al. Cholesterol variability and the risk of mortality, myocardial infarction, and stroke: a nationwide population-based study. Eur Heart J. 2017 Dec;38(48): 3560-6.

16 Shepherd J, Kastelein JJ, Bittner V, Deedwania P, Breazna A, Dobson S, et al.; Treating to New Targets Investigators. Effect of intensive lipid lowering with atorvastatin on renal function in patients with coronary heart disease: the Treating to New Targets (TNT) study. Clin J Am Soc Nephrol. 2007 Nov;2(6):1131-9.

17 Sandhu S, Wiebe N, Fried LF, Tonelli M. Statins for improving renal outcomes: a meta-analysis. J Am Soc Nephrol. 2006 Jul;17(7):2006-16.

18 Yokota K, Fukuda M, Matsui Y, Kario K, Kimura K. Visit-to-visit variability of blood pressure and renal function decline in patients with diabetic chronic kidney disease. J Clin Hypertens (Greenwich). 2014 May;16(5): 362-6.

19 Chia YC, Lim HM, Ching SM. Long-Term Visit-to-Visit Blood Pressure Variability and Renal Function Decline in Patients With Hypertension Over 15 Years. J Am Heart Assoc. 2016 Nov;5(11):5.

20 Parati G, Ochoa JE, Bilo G. Blood pressure variability, cardiovascular risk, and risk for renal disease progression. Curr Hypertens Rep. 2012 Oct;14(5):421-31.

21 Samuelsson O, Mulec H, Knight-Gibson C, Attman PO, Kron B, Larsson R, et al. Lipoprotein abnormalities are associated with increased rate of progression of human chronic renal insufficiency. Nephrol Dial Transplant. 1997 Sep;12(9):1908-15.

22 Mancia G, Fagard R, Narkiewicz K, Redán J, Zanchetti A, Böhm M, et al.; ESH/ESC Task Force for the Management of Arterial Hypertension. 2013 Practice guidelines for the management of arterial hypertension of the European Society of Hypertension (ESH) and the European Society of Cardiology (ESC): ESH/ESC Task Force for the Management of Arterial Hypertension. J Hypertens. 2013 Oct;31(10):1925-38.

23 Ma YC, Zuo L, Chen JH, Luo Q, Yu XQ, Li Y, et al. Modified glomerular filtration rate estimating equation for Chinese patients with chronic kidney disease. J Am Soc Nephrol. 2006 Oct;17(10):2937-44.

24 Xu X, Qin X, Li Y, Sun D, Wang J, Liang M, et al.; investigators of the Renal Substudy of the China Stroke Primary Prevention Trial (CSPPT). Efficacy of Folic Acid Therapy on the Progression of Chronic Kidney Disease: The Renal Substudy of the China Stroke Primary Prevention Trial. JAMA Intern Med. 2016 Oct;176(10):1443-50.

25 Diaz KM, Tanner RM, Falzon L, Levitan EB, Reynolds K, Shimbo D, et al. Visit-to-visit variability of blood pressure and cardiovascular disease and all-cause mortality: a systematic review and meta-analysis. Hypertension. 2014 Nov;64(5):965-82.

26 Bangalore S, Fayyad R, Messerli FH, Laskey R, DeMicco DA, Kastelein JJ, et al. Relation of Variability of LowDensity Lipoprotein Cholesterol and Blood Pressure to Events in Patients With Previous Myocardial Infarction from the IDEAL Trial. Am J Cardiol. 2017 Feb;119(3):379-87. 
27 Kim MK, Han K, Koh ES, Kim HS, Kwon HS, Park YM, et al. Variability in Total Cholesterol Is Associated With the Risk of End-Stage Renal Disease: A Nationwide Population-Based Study. Arterioscler Thromb Vasc Biol. 2017 Oct;37(10):1963-70.

28 Vlassara H, Torreggiani M, Post JB, Zheng F, Uribarri J, Striker GE. Role of oxidants/inflammation in declining renal function in chronic kidney disease and normal aging. Kidney Int Suppl. 2009 Dec;76(114):S3-11.

29 Muntner P, Coresh J, Smith JC, Eckfeldt J, Klag MJ. Plasma lipids and risk of developing renal dysfunction: the atherosclerosis risk in communities study. Kidney Int. 2000 Jul;58(1):293-301.

30 Perticone F, Maio R, Perticone M, Sciacqua A, Shehaj E, Naccarato P, et al. Endothelial dysfunction and subsequent decline in glomerular filtration rate in hypertensive patients. Circulation. 2010 Jul;122(4):379-84.

31 Satoh M. Endothelial dysfunction as an underlying pathophysiological condition of chronic kidney disease. Clin Exp Nephrol. 2012 Aug;16(4):518-21.

32 Diamond JR, Karnovsky MJ. Focal and segmental glomerulosclerosis: analogies to atherosclerosis. Kidney Int. 1988 May;33(5):917-24.

33 Tsimihodimos V, Mitrogianni Z, Elisaf M. Dyslipidemia associated with chronic kidney disease. Open Cardiovasc Med J. 2011;5(1):41-8. 